\title{
WIN 55,212-2 shows anti-inflammatory and survival properties in human iPSC-derived cardiomyocytes infected with SARS- CoV-2
}

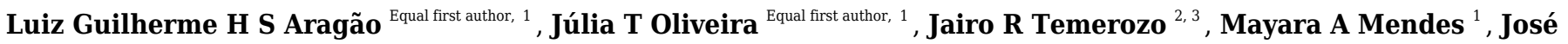
Alexandre Salerno ${ }^{4}$, Carolina S G Pedrosa ${ }^{1}$, Teresa Puig-Pijuan ${ }^{1,5}$, Carla P Veríssimo ${ }^{4}$, Isis M Ornelas ${ }^{1}$, Thayana Torquato $^{1}$, Gabriela Vitória ${ }^{1}$, Carolina Q Sacramento ${ }^{3,6}$, Natalia Fintelman-Rodrigues ${ }^{3,6}$, Suelen da Silva Gomes Dias ${ }^{6}$, Vinicius Cardoso Soares ${ }^{6,7}$, Letícia R Q Souza ${ }^{1}$, Karina Karmirian ${ }^{1,4}$, Livia Goto-Silva ${ }^{1}$, Diogo Biagi ${ }^{8}$, Estela M Cruvinel $^{8}$, Rafael Dariolli ${ }^{8,9}$, Daniel R Furtado ${ }^{1}$, Patrícia T Bozza ${ }^{6}$, Helena L Borges ${ }^{4}$, Thiago Moreno L Souza ${ }^{3,}$ ${ }^{6}$, Marília Zaluar P Guimarães ${ }^{1,4}$, Stevens K Rehen ${ }^{\text {Corresp. } 1,10}$

1 D'Or Institute for Research and Education (IDOR), Rio de Janeiro, Rio de Janeiro, Brazil

2 Laboratory on Thymus Research, Oswaldo Cruz Institute (IOC), Rio de Janeiro, Rio de Janeiro, Brazil

3 National Institute for Science and Technology on Innovation in Diseases of Neglected Populations (INCT/IDPN), Center for Technological Development in Health (CDTS), Oswaldo Cruz Foundation (Fiocruz), Rio de Janeiro, Rio de Janeiro, Brazil

4 Institute of Biomedical Sciences, Federal University of Rio de Janeiro (UFRJ), Rio de Janeiro, Rio de Janeiro, Brazil

5 Carlos Chagas Filho Institute of Biophysics, Federal University of Rio de Janeiro (UFRJ), Rio de Janeiro, Rio de Janeiro, Brazil

6 Laboratory of Immunopharmacology, Oswaldo Cruz Institute (IOC), Oswaldo Cruz Foundation (Fiocruz), Rio de Janeiro, Rio de Janeiro, Brazil

7 Program of Immunology and Inflammation, Federal University of Rio de Janeiro (UFRJ), Rio de Janeiro, Rio de Janeiro, Brazil

8 Pluricell Biotech, São Paulo, São Paulo, Brazil

9 Department of Pharmacological Sciences, Icahn School of Medicine at Mount Sinai, New York, New York, United States

10 Department of Genetics, Institute of Biology, Federal University of Rio de Janeiro (UFRJ), Rio de Janeiro, Rio de Janeiro, Brazil

Corresponding Author: Stevens K Rehen

Email address: srehen@lance-ufrj.org

Coronavirus disease 2019 (COVID-19) is caused by severe acute respiratory syndrome coronavirus 2 (SARS-CoV-2), which can infect several organs, especially impacting respiratory capacity. Among the extrapulmonary manifestations of COVID-19 is myocardial injury, which is associated with a high risk of mortality. Myocardial injury, caused directly or indirectly by SARS-CoV-2 infection, can be triggered by inflammatory processes that cause damage to the heart tissue. Since one of the hallmarks of severe COVID-19 is the "cytokine storm", strategies to control inflammation caused by SARS-CoV-2 infection have been considered. Cannabinoids are known to have anti-inflammatory properties by negatively modulating the release of pro-inflammatory cytokines. Herein, we investigated the effects of the cannabinoid agonist WIN 55,212-2 (WIN) in human iPSC-derived cardiomyocytes (hiPSC-CMs) infected with SARS-CoV-2. WIN did not modify angiotensinconverting enzyme II protein levels, nor reduced viral infection and replication in hiPSCCMs. On the other hand, WIN reduced the levels of interleukins $6,8,18$ and tumor necrosis factor-alpha (TNF- $\alpha$ ) released by infected cells, and attenuated cytotoxic damage measured by the release of lactate dehydrogenase (LDH). Our findings suggest that Peer] reviewing PDF | (2021:06:62450:1:0:NEW 7 Sep 2021) 
cannabinoids should be further explored as a complementary therapeutic tool for reducing inflammation in COVID-19 patients. 
WIN 55,212-2 shows anti-inflammatory and survival properties in human iPSCderived cardiomyocytes infected with SARS-CoV-2

3 Luiz Guilherme H. S. Aragão1 ${ }^{1 \pi}$, Júlia T. Oliveira1 ${ }^{1}$, Jairo R. Temerozo ${ }^{2,3}$, Mayara A. Mendes ${ }^{1}$, José 4 Alexandre Salerno ${ }^{1,10}$, Carolina da S. G. Pedrosa ${ }^{1}$, Teresa Puig-Pijuan ${ }^{1,8}$, Carla P. Veríssimo ${ }^{10}$, Isis M. 5 Ornelas $^{1}$, Thayana Torquato ${ }^{1}$, Gabriela Vitória ${ }^{1}$, Carolina Q. Sacramento ${ }^{4,5}$, Natalia Fintelman6 Rodrigues $^{4,5}$, Suelen da Silva Gomes Dias ${ }^{4}$, Vinicius Cardoso Soares ${ }^{4,6}$, Leticia R. Q. Souza ${ }^{1}$, Karina 7 Karmirian $^{1,10}$, Livia Goto-Silva ${ }^{1}$, Diogo Biagi ${ }^{7}$, Estela M. Cruvinel ${ }^{7}$, Rafael Dariolli ${ }^{7,9}$, Daniel R. Furtado ${ }^{1}$, 8 Patrícia T. Bozza ${ }^{4}$, Helena L. Borges ${ }^{10}$, Thiago Moreno L. Souza ${ }^{4,5}$, Marília Zaluar P. Guimarães ${ }^{1,10, \&^{*}}$ \& 9 Stevens Rehen ${ }^{1,11, \&^{*}}$

1 D'Or Institute for Research and Education (IDOR), Rio de Janeiro, RJ, Brazil.

112 National Institute for Science and Technology on Neuroimmunomodulation (INCT/NIM), Oswaldo Cruz 12 Institute (IOC), Oswaldo Cruz Foundation (Fiocruz), Rio de Janeiro, RJ, Brazil.

${ }^{3}$ Laboratory on Thymus Research, Oswaldo Cruz Institute (IOC), Oswaldo Cruz Foundation (Fiocruz), Rio 14 de Janeiro, RJ, Brazil.

${ }^{4}$ Laboratory of Immunopharmacology, Oswaldo Cruz Institute (IOC), Oswaldo Cruz Foundation (Fiocruz), Rio de Janeiro, RJ, Brazil.

5 National Institute for Science and Technology on Innovation in Diseases of Neglected Populations (INCT/IDPN), Center for Technological Development in Health (CDTS), Oswaldo Cruz Foundation (Fiocruz), Rio de Janeiro, RJ, Brazil.

${ }^{6}$ Program of Immunology and Inflammation, Federal University of Rio de Janeiro, UFRJ, Rio de Janeiro, 21 RJ, Brazil.

7 Pluricell Biotech, São Paulo, SP, Brazil.

${ }^{8}$ Carlos Chagas Filho Institute of Biophysics, Federal University of Rio de Janeiro (UFRJ), Rio de Janeiro, 24 RJ, Brazil.

${ }^{9}$ Department of Pharmacological Sciences, Icahn School of Medicine at Mount Sinai, New York, NY, United 26 States.

2710 Institute of Biomedical Sciences, Federal University of Rio de Janeiro (UFRJ), Rio de Janeiro, RJ, Brazil.

${ }^{11}$ Department of Genetics, Institute of Biology, Federal University of Rio de Janeiro (UFRJ), Rio de Janeiro, 29 RJ, Brazil. 
31

32 I These authors contributed equally to this work

$33 \&$ These authors contributed equally to this work.

34 *Corresponding author: srehen@lance-ufrj.org, UFRJ and D'Or Institute for Research and Education

35

36

37

38

39

40

41

42

43

44

45

46

47

48

Peer) reviewing PDF | (2021:06:62450:1:0:NEW 7 Sep 2021) 
Abstract

Coronavirus disease 2019 (COVID-19) is caused by severe acute respiratory syndrome coronavirus 2 (SARS-CoV-2), which can infect several organs, especially impacting respiratory capacity. Among the extrapulmonary manifestations of COVID-19 is myocardial injury, which is associated with a high risk of mortality. Myocardial injury, caused directly or indirectly by SARS-CoV-2 infection, can be triggered by inflammatory processes that cause damage to the heart tissue. Since one of the hallmarks of severe COVID-19 is the "cytokine storm", strategies to control inflammation caused by SARSCoV-2 infection have been considered. Cannabinoids are known to have antiinflammatory properties by negatively modulating the release of pro-inflammatory cytokines. Herein, we investigated the effects of the cannabinoid agonist WIN 55,212-2 (WIN) in human iPSC-derived cardiomyocytes (hiPSC-CMs) infected with SARS-CoV-2. WIN did not modify angiotensin-converting enzyme II protein levels, nor reduced viral infection and replication in hiPSC-CMs. On the other hand, WIN reduced the levels of interleukins 6, 8, 18 and tumor necrosis factor-alpha (TNF- $\alpha$ ) released by infected cells, and attenuated cytotoxic damage measured by the release of lactate dehydrogenase (LDH). Our findings suggest that cannabinoids should be further explored as a complementary therapeutic tool for reducing inflammation in COVID-19 patients. 


\section{Introduction}

81 The causative agent of Coronavirus disease 2019 (COVID-19), SARS-CoV-2, can affect

82 multiple organs, including lungs, nervous system (Carod-Artal, 2020), digestive system

83 (Chen et al., 2020b), urinary system (Puelles et al., 2020), skin (Mahé et al., 2020; Diaz-

84 Guimaraens et al., 2020) and heart (Maisch, 2020; Varga et al., 2020; Zheng et al., 2020).

85 A post-mortem study of a child with COVID-19 revealed diffuse myocardial interstitial 86 inflammation with immune cells infiltration and necrosis (Dolhnikoff, 2020). Recently, we 87 showed cardiac damage, namely microthrombi in small arteries and focal mild 88 lymphocytic infiltrate in the ventricles, of an infant who died of COVID-19 (Gomes et al., 89 2020). Another study detected SARS-CoV-2 in myocardial tissue, which expressed 90 inflammatory mediators, such as tumor necrosis factor-alpha (TNF- $\alpha$ ), interferon-gamma

91 (IFN-Y), chemokine ligand 5, as well as interleukin (IL) -6, -8, and -18 (Lindner et al., 92 2020). Additionally, patients with COVID-19 presented elevated levels of creatine kinase 93 and lactate dehydrogenase (LDH) activity, which are biomarkers of heart injury (Chen et 94 al., 2020b; Zhou et al., 2020).

95 High expression of Angiotensin-Converting Enzyme II (ACE2) in the heart has been 96 correlated with severe COVID-19 and susceptibility of patients with pre-existing cardiac 
97 conditions (Chen et al., 2020a; Thum, 2020; Sharma et al., 2020; Dariolli et al., 2021). In

98 vitro studies have shown that SARS-CoV-2 infects iPSC-derived cardiomyocytes (hiPSC-

99 CMs) through ACE2 (Sharma et al., 2020; Dariolli et al., 2021), leading to upregulation of

100 inflammation-related genes, including IL-6, IL-8, and TNF- $\alpha$ (Wong et al., 2020; Kwon et

101 al., 2020). The increase in proinflammatory cytokines can cause several adverse effects

102 in cardiomyocytes including arrhythmia (Keck et al., 2019), cellular hypertrophy (Smeets

103 et al., 2008), cell death (Wang et al., 2016), conversion of fibroblasts into myofibroblasts

104 (Wang et al., 2016) and alteration of action potentials' duration (Aromolaran et al., 2018).

105 The correlation between inflammation and heart damage in post-mortem and in in vitro

106 studies points to the need for finding strategies that mitigate direct SARS-CoV-2 cardiac

107 outcomes.

108 For many centuries Cannabis $s p$. has been used for medicinal purposes and, more

109 recently, it has been investigated as a therapeutic agent for cardiovascular diseases

110 (Mendizábal \& Adler-Graschinsky, 2007; Pacher et al., 2018). Cannabis has several

111 known compounds, named phytocannabinoids, including delta-9-tetrahydrocannabinol

112 (THC), which is the most abundant and the main psychoactive ingredient, followed in

113 amount by cannabidiol (CBD). Besides phytocannabinoids, there is intensive research on

114 endocannabinoids, such as anandamide and 2-arachidonoylglycerol, and synthetic

115 cannabinoids, such as WIN 55,212-2 (WIN). Nguyen et al., (2021) showed the potential

116 of cannabinoids to decrease SARS-CoV-2 infection, viral replication, and inflammation

117 that are directly related to COVID-19 severity. Treatment with Cannabis extracts

118 decreased ACE2 expression in oral, intestinal, and airway epithelia in vitro (Wang et al.,

119 2020). It is noteworthy that cannabinoids have anti-inflammatory properties and exert their 
120 biological effect mainly by interaction with the cannabinoid receptors type 1 (CB1) and/or

121 type 2 (CB2), to both of which WIN has high affinity and efficacy (Devane et al., 1988;

122 Munro, Thomas \& Abu-Shaar, 1993; Felder et al., 1995; Soethoudt et al. 2017; Sachdev

123 et al., 2019). For instance, WIN was shown to reduce the number of lipopolysaccharide-

124 activated microglia in the brain of an animal model of chronic inflammation (Marchalant,

125 Rosi \& Wenk, 2007). Another work showed that WIN decreased TNF- $\alpha$ and IL-6 plasma

126 levels and myeloperoxidase activity in mice with experimental colitis (Feng et al., 2016).

127 An extract fraction from Cannabis sativa Arbel strain enriched in CBD, cannabigerol and

128 tetrahydrocannabivarin presented anti-inflammatory activity in lung epithelial cells treated

129 with TNF- $\alpha$ but another fraction with high CBD containing terpenes in addition to

130 phytocannabinoids enhanced proinflammatory parameters of macrophages (Anil et al.,

131 2021). Additionally, high-CBD Cannabis sativa extracts presented anti-inflammatory

132 properties in the epithelia pretreated with TNF- $\alpha$ and IFN-y (Lei et al., 2020). Smith et al.

133 (2000) showed that treatment with WIN decreased serum TNF- $\alpha$ and IL-12 and increased

134 IL-10 through the CB1 receptor in mice treated with lipopolysaccharide (Smith, Terminelli

135 \& Denhardt, 2000). Investigating the anti-inflammatory potential of Cannabis sativa in

136 cardiomyocytes is important because the "cytokine storm" is a hallmark of COVID-19 and

137 the cardiovascular system is mostly affected in severe cases (Unudurthi et al., 2020). To

138 date, the effects of cannabinoids in human cardiomyocytes infected with SARS-CoV-2

139 has not been addressed.

140 In this work, we aimed to investigate the effects of a synthetic cannabinoid, that acts as

141 a mixed CB1/CB2 receptors agonist, in hiPSC-CMs infected by SARS-CoV-2. WIN

142 presented anti-inflammatory and protective properties by reducing the levels of 
143 proinflammatory cytokines and cell death in hiPSC-CM but did neither modulate ACE2

144 nor reduced SARS-CoV-2 infection and replication. Our data suggest that the anti-

145 inflammatory and protective properties of WIN may be used to control inflammation and

146 tissue damage during SARS-CoV-2 infection of heart cells.

Materials \& Methods

151

Chemical

152 WIN 55,212-2 mesylate was purchased from TargetMol (T4458). Stock solutions were

153 prepared using 100\% dimethyl sulfoxide (DMSO; D2650 - Sigma-Aldrich) and sterile-

154 filtered. The final concentration of DMSO in work solution was $0.01 \%$.

155 iPS-Cardiomyocyte differentiation and purification

156 hiPSC-CMs were purchased from Pluricell (São Paulo, Brazil) and used between day 25

157 and day 35 of differentiation. The hiPSC-CMs used here were generated and previously 158 characterized in vitro by Cruvinel et al. (2020). Briefly, the enrichment of the

159 cardiomyocyte population was assessed by flow cytometry and immunofluorescence of

160 TNNT2, a specific marker, which revealed that, on average, $88.4 \%(+/-8.4 \%)$ cells were

161 positive cells (Fig S3). hiPSC-CMs were handled in four different groups: MOCK and

162 SARS-CoV-2 (SARS-CoV-2 infection without WIN), which were also analyzed as controls

163 in Salerno et al. (2021), MOCK WIN (no SARS-CoV-2 infection + WIN), and SARS-CoV-2 
164 WIN (SARS-Cov-2 infection + WIN). All WIN-treated hiPSC-CMs were pretreated for 24

165 hours with $1 \mu \mathrm{M}$ WIN. Fresh culture medium with (or without) $1 \mu \mathrm{M}$ WIN, combined or not

166 with SARS-CoV-2, was added for 24 hours to each experimental group, respectively.

167 SARS-CoV-2 propagation

168 SARS-CoV-2 was expanded in Vero E6 cells from an isolate of a nasopharyngeal swab

169 obtained from a confirmed case in Rio de Janeiro, Brazil (GenBank accession no.

170 MT710714). Viral isolation was performed after a single passage in $150 \mathrm{~cm}^{2}$ flasks

171 cultured with high glucose DMEM plus $2 \%$ FBS. Observations for cytopathic effects were

172 performed daily and peaked 4 to 5 days after infection. All procedures related to virus

173 culture were handled in biosafety level 3 (BSL3) multi-user facilities according to WHO

174 guidelines. Virus titers were determined as plaque-forming units (PFU/mL) as explained

175 below, and virus stocks were kept at $-80^{\circ} \mathrm{C}$.

176 SARS-CoV-2 titration

177 For virus titration, monolayers of Vero E6 cells $\left(2 \times 10^{4}\right.$ cell/well) in 96-well plates were

178 infected with serial dilutions of supernatants containing SARS-CoV-2 for 1 hour at $37^{\circ} \mathrm{C}$.

179 A semi-solid high glucose DMEM medium containing $2 \% \quad$ FSB and $2.4 \%$

180 carboxymethylcellulose was added and cultures were incubated for 3 days at $37^{\circ} \mathrm{C}$.

181 Then, the cells were fixed with $10 \%$ formalin for 2 hours at room temperature. The cell

182 monolayer was stained with $0.04 \%$ solution of crystal violet in $20 \%$ ethanol for 1 hour.

183 Plaque numbers were scored in at least 3 replicates per dilution by independent readers

184 blinded to the experimental group and the virus titers were determined by plaque-forming 185 units (PFU) per milliliter. 
187 hiPSC-CMs were infected with SARS-CoV-2 at a multiplicity of infection (MOI) of 0.1 in

188 high glucose DMEM without serum. After 1 hour, cells were washed and incubated with

189 Complete Medium with or without treatments for 48-72h. Next, the supernatant was

190 collected, and cells were fixed with $4 \%$ paraformaldehyde (PFA) solution for posterior

191 analysis.

192 Measurement of cytokines mediators and LDH cytotoxicity

193 Cytokines (IL-6, IL-7, IL-8, and TNF- $\alpha$ ) were quantified in the supernatants from hiPSC-

194 CMs samples by ELISA (R\&D Systems) following manufacturer's instructions. The

195 analysis of data was performed using software provided by the manufacturer (Bio-Rad

196 Laboratories, USA). A range of $0.51-8,000 \mathrm{pg} / \mathrm{mL}$ recombinant cytokines was used to

197 establish standard curves and the sensitivity of the assay. Cell death was determined

198 according to the activity of lactate dehydrogenase (LDH) in the culture supernatants using

199 a CytoTox® Kit (Promega, USA) according to the manufacturer's instructions.

200 Gene expression analysis

201 Qualitative endpoint PCR reactions were executed with the following primer sequences:

202 CB1 (forward 5'-ATGTGGACCATAGCCATTGTG-3'; reverse: 5'-

203 CCGATCCAGAACATCAGGTAGG-3') and CB2 (forward 5'-

204 GCTATCCACCTTCCTACAAAGC-3'; reverse: 5'- CTCAGCAGGTAGTCATTGGGG-3').

205 Glyceraldehyde-3-phosphate Dehydrogenase (GAPDH; forward: 5'-

206 TTCGACAGTCAGCCGCATC-3'; reverse: 5'-GACTCCACGACGTACTCAGC-3') was

207 used as the endogenous housekeeping control gene. Each PCR reaction was performed 
208 in a $10 \mu \mathrm{L}$ mixture containing $0.25 \mathrm{U}$ GoTaq G2 Hot Start Polymerase (Promega), 1x

209 GoTaq G2 Buffer, $1.5 \mathrm{mM} \mathrm{MgCl} 2$ (Invitrogen), $200 \mathrm{nM}$ of each primer (forward and

210 reverse), $200 \mu \mathrm{M}$ dNTP mixture containing the four deoxyribonucleotides (dATP, dCTP,

211 dTTP, and dGTP), and $10 \mathrm{ng}$ of cDNA template. Appropriate negative controls and

212 genomic DNA positive controls were incorporated into each experiment. Amplification

213 thermal program included an initial denaturation step of $95^{\circ} \mathrm{C}$ for 3 minutes and 40 cycles

214 of $95^{\circ} \mathrm{C}$ for 15 seconds, $60^{\circ} \mathrm{C}$ for 15 seconds and $72^{\circ} \mathrm{C}$ for 15 seconds using the

215 ProFlexTM PCR System Thermal Cycler (Applied Biosystems). Subsequently, the total

216 amount of PCR product was separated by electrophoresis at $110 \mathrm{~V}$ for 40 minutes in $1.8 \%$

217 agarose gel diluted in $1 \times$ Tris-acetate EDTA buffer $(\mathrm{w} / \mathrm{v})$ and stained with $0.01 \%$ of SYBR

218 Safe (Thermo Fisher).

219 For real-time quantitative PCR, the reactions were carried out in triplicates in a reaction 220 mixture containing 1x GoTaq qPCR MasterMix (Promega Corporation), 300 nM CXR

221 Reference Dye, a final concentration of $200 \mathrm{nM}$ of each (forward and reverse) SYBR 222 green-designed primers (Thermo Fisher Scientific), and $10 \mathrm{ng}$ of cDNA template per

223 reaction. Appropriate negative controls were added in each run. The relative expression

224 of the genes of interest: ACE2 (forward: 5'-CGAAGCCGAAGACCTGTTCTA-3'; reverse:

225

5'-GGGCAAGTGTGGACTGTTCC-3'),

MYH6

(forward:

5'-

226 GCCCTTTGACATTCGCACTG-3'; reverse: 5'- GGTTTCAGCAATGACCTTGCC-3'),

227 MYH7 (forward: 5'- TCACCAACAACCCCTACGATT-3'; reverse: 5'-

228 CTCCTCAGCGTCATCAATGGA-3') was normalized by human reference genes:

229 Glyceraldehyde-3-phosphate Dehydrogenase (GAPDH; forward: 5'-

230 GCCCTCAACGACCACTTTG-3'; reverse: 5'-CCACCACCCTGTTGCTGTAG-3') and 
231 Hypoxanthine Phosphoribosyltransferase 1 (HPRT-1; forward 5'-

232 CGTCGTGATTAGTGATGATGAACC-3'; reverse: 5'-AGAGGGCTACAATGTGATGGC-

$\left.2333^{\prime}\right)$. The reactions were performed on a StepOnePlusTM Real-Time PCR System

234 thermocycler (Applied Biosystems). Thermal cycling program comprised of a denaturing

235 step at $95^{\circ} \mathrm{C}$ for 3 minutes, followed by 40 cycling stages at $95^{\circ} \mathrm{C}$ for 15 seconds, $57^{\circ} \mathrm{C}$

236 for 15 seconds, $72^{\circ} \mathrm{C}$ for 15 seconds and melt curve stage $95{ }^{\circ} \mathrm{C}, 15$ seconds; $60{ }^{\circ} \mathrm{C}, 1$

237 minutes; $95^{\circ} \mathrm{C}, 15$ seconds. Data analysis was performed with LinRegPCR quantitative

238 PCR data analysis program v. 2020.0, as previously described.

240 Immunofluorescence staining

241 SARS-CoV-2-infected and mock-treated hiPSC-CMs were fixed using 4\%

242 paraformaldehyde solution (Sigma-Aldrich, EUA) for 1 hour and stored at $4^{\circ} \mathrm{C}$. Next, cells

243 were washed with PBS and then incubated with permeabilization/blocking solution $(0.3 \%$

244 Triton X-100 / 1\% bovine serum albumin $+3 \%$ normal goat serum) for 1 hour.

245 Cardiomyocytes were incubated with primary antibodies diluted in a blocking buffer

246 solution at $4^{\circ}$ overnight: anti-SARS-CoV-2 convalescent serum from a positive COVID-

24719 patient (1:1000) and anti-cardiac troponin T (TNNT2) (1:500, MA5-12960 - Invitrogen).

248 Afterwards, cardiomyocytes were incubated with the secondary antibody diluted in a

249 blocking buffer solution: goat anti-Human Alexa Fluor 647 (1:400; A-21445 - Invitrogen)

250 and goat anti-Mouse 594 (1:400; A-11032 - Invitrogen) for 1 hour. Actin filaments were

251 stained with Alexa Fluor 568 phalloidin (1:10; A-12380 - Life Technologies) for 1 hour.

252 Nuclei were stained with $300 \mathrm{nM} \mathrm{4'-6-diamino-2-phenylindole} \mathrm{(DAPI)} \mathrm{for} 5$ minutes and 
253 each well was mounted with two drops of $50 \%$ PBS-Glycerol. Images (at least 10 fields

254 per well) of hiPSC-CMs were acquired using Operetta ${ }^{\circledR}$ High-Content Imaging System

255 (Perkin Elmer) with a 20x long working distance (WD) objective lens. A Leica TCS-SP8

256 confocal microscope was used to acquire images of hiPSC-CMs immunostained for

257 TNNT2 and F-actin with the 63x objective (Fig S3).

258 Neutral red uptake cell viability assay

259 Briefly, hiPSC-CMs were seeded in 96 -well plates. After reaching $80-90 \%$ confluency, 260 cells were exposed to concentrations of WIN ranging between $10 \mathrm{nM}-10 \mu \mathrm{M}$ for 72 hours.

261 Next, the medium was replaced, cells were washed with PBS $1 \mathrm{x}$ and $200 \mu \mathrm{L}$ of neutral

262 red dye diluted in the hiPSC-CMs medium was added to each well at a final concentration

263 of $0.05 \mathrm{mg} / \mathrm{mL}$. After 3 hours of incubation at $37^{\circ} \mathrm{C}$, neutral red dye was removed, and

264 the cells were washed again. Then, $100 \mu \mathrm{L}$ of the neutral red desorb solution was

265 added (1\% acetic acid- $49 \%$ ethanol) to the wells, followed by 20 minutes in orbital

266 shaking. Absorbance at $540 \mathrm{~nm}$ was measured with a Tecan Infinite ${ }^{\circledR} 200$ PRO (Life

267 Sciences, Switzerland) spectrophotometer.

268 Western Blotting

269 Twenty-four hours after treatment with WIN of hiPSC-CMs in 24-well plates, $100 \mu \mathrm{L}$ of

270 sample buffer without bromophenol blue $(62.5 \mathrm{mM}$ Tris- $\mathrm{HCl}, \mathrm{pH} 6.8$, containing $10 \%$

271 glycerol, 2\% SDS, and 5\% 2-mercaptoethanol) was added in each well, and a cell scraper

272 was used to help lyse the cells. Cell extracts were transferred to an Eppendorf tube,

273 boiled at $95^{\circ} \mathrm{C}$ for 5 minutes, and centrifuged at $4^{\circ} \mathrm{C} 16,000 \mathrm{xg}$ for 15 minutes to collect

274 the supernatant. Protein content was estimated using the Bio-Rad Protein Assay (\# 
275 5000006, Biorad). Next, bromophenol blue (0.02\%) was added, and extracted samples

276 (40 $\mu \mathrm{g} / \mathrm{lane})$ were separated by an $8 \%$ SDS polyacrylamide gel electrophoresis and

277 transferred to polyvinylidene difluoride (PVDF) membranes. The membranes were

278 blocked in 5\% non-fat milk in Tris Buffered Saline with 0.1\% Tween-20 (TBS-T) for 1 hour

279 at room temperature. Then, membranes were incubated overnight at $4^{\circ} \mathrm{C}$ with primary

280 antibodies anti-ACE2 (1: 1000; MA5-32307 - Thermo Fisher), anti-CB1 (1:300, CSB-

281 PA007048, Cusabio), and anti-ACTIN (1:2000; MAB1501, Millipore), diluted in TBS-T with

$2825 \%$ non-fat milk. Membranes were washed and incubated with peroxidase-conjugated

283 antibodies IgG $(H+L)$, HRP-conjugate: goat anti-mouse (1: 10.000, G21040, Molecular

284 Probes), goat anti-rabbit (1: 10.000, G21234, Molecular Probes), and rabbit anti-goat (1:

$2852.000,61-1620$, Invitrogen) for 2 hours at room temperature. The signals were developed

286 using an ECL Prime Western Blotting System (\# GERPN2232, Sigma) for 5 minutes, and

287 chemiluminescence was detected with an Odyssey-FC Imaging System ${ }^{\circledR}$ (LI-COR

288 Biosciences, EUA). After CB1 or CB2 detection a stripping protocol was used on the

289 membranes for further detection of actin. Membranes were incubated with a stripping

290 buffer $(\mathrm{pH} 2.2,200 \mathrm{mM}$ glycine, 0.1\% SDS, and 1\% Tween-20) for three cycles of 10

291 minutes. Next, the buffer was discarded, and the membranes were washed three times

292 with PBS and three times for 5 minutes with $0.1 \%$ TBS-T. Then, membranes were blocked

293 again and proceeded with the above-described steps.

294 Statistics

295 Statistical analyses were performed using GraphPadPrism software version 8.0

296 (GraphPad, EUA). Results were expressed as the mean and standard error of the mean

297 (SEM). For comparisons between two experimental groups, unpaired two-tailed Student's 
298 t-test or Mann-Whitney U test was used, whereas two-way analysis of variance (ANOVA)

299 or Kruskal-Wallis test followed by Tukey's test was used for comparisons between three

300 or more groups. A p-value smaller than 0.05 was accepted as statistically significant.

301 Ethics Statement

302 Approved by the Research Ethics Committee of D'Or Institute of Research and Education

303 (IDOR) 39474020.8.0000.5249.

\section{Results}

1. Human cardiomyocytes express cannabinoid receptor 1 but WIN does not modulate ACE2 expression

311 As a first step to investigate the influence of cannabinoid receptors in SARS-CoV-2

312 infection of human cardiomyocytes, we checked whether hiPSC-CMs expressed CB1 and

313 CB2 receptors. We found that hiPSC-CMs express only CB1 receptor mRNA (Fig S1A),

314 which was confirmed by CB1 protein expression (Fig S1B). The banding pattern observed

315 in the hiPSC-CMs was similar to the mouse hippocampus sample (positive control) and

316 consistent with what was observed in samples from other CNS regions (Medina-Vera et

317 al., 2020). 
318 WIN is an agonist at the CB1 and CB2 receptors with a higher affinity to them than other

319 cannabinoids (Acheson et al., 2011; Sachdev., 2019), including THC (Felder et al. 1995)

320 and therefore it is an useful pharmacological tool to study cannabinoid receptor activation.

321 Beforehand, we tested multiple WIN concentrations in readouts of cellular toxicity and

322 permanent cardiac hypertrophy. We found that WIN did not reduce cell viability in

323 concentrations up to $1 \mu \mathrm{M}$ (Fig S3A). Also, compared with control, $1 \mu \mathrm{M}$ WIN did not

324 increase MYH6 and MYH7 mRNA levels (Fig S3B), genes that, when upregulated, may

325 indicate cardiac hypertrophy in vitro (Wenzel, 1967; Rahmatollahi et al., 2016; Albakri,

326 2019). Therefore, we chose $1 \mu \mathrm{M}$ WIN as the usage concentration for further assays since

327 it caused neither cell death nor changes in gene expression related to hypertrophy.

328 After confirming that hiPSC-CMs express CB1 and ACE2 (Salerno et al., 2021), we asked

329 whether WIN modulates ACE2 expression and, subsequently, influences SARS-CoV-2

330 infection within hiPSC-CMs. hiPSC-CMs were pretreated with $1 \mu \mathrm{M} \mathrm{WIN}$ for 24 hours and

331 analyzed for both mRNA and protein levels of ACE2. We observed that WIN-treated (1.15

$332 \pm 0.07$ A.U.) and untreated $(0.98 \pm 0.11$ A.U.) hiPSC-CMs had comparable levels of ACE2

333 mRNA whereas ACE2 protein levels in WIN treated cells whereas ACE2 protein levels in

334 WIN treated cells was $1.16 \pm 0.39$, normalized to control (Fig 1A, B and C, and Fig S2).

\section{WIN does not influence SARS-CoV-2 infection and replication in hiPSC-CMs}

336 Next, we asked whether WIN could reduce hiPSC-CMs SARS-CoV-2 infection by

337 mechanisms other than ACE2 modulation. For this, cells were pretreated with $1 \mu \mathrm{M}$ WIN

338 for 24 hours and infected with SARS-CoV-2 at a multiplicity of infection (MOI) of 0.1 for 1

339 hour, and the PFU analyzed 48 hours later. In this study, we defined the use of MOI 0.1

340 for all experiments because this MOI had already been successfully used to infect hiPSC- 
341 CMs with SARS-CoV-2 (Sharma et al., 2020). Additionally, MOls above 0.1 may not be

342 a clinically plausible viral load found in vivo. Forty-eight hours after infection, we quantified

343 convalescent serum (CS)-immunostaining and, as expected, we found that cells in the

344 MOCK group had no CS immunoreactivity. Among the SARS-CoV-2-infected cells, those

345 pretreated with WIN had a comparable percentage of infected cells (WIN SARS-CoV-2;

$34630 \pm 15 \%$ ) to those untreated (SARS-CoV-2; $26 \pm 12 \%$ ) (Fig 2A and B).

347 Since viral infection and replication are correlated but orchestrated by different

348 mechanisms, we asked whether WIN could decrease SARS-CoV-2 replication in hiPSC-

349 CMs. We observed that despite a decrease in average viral titer when comparing SARS-

350 CoV-2 WIN $\left(6.99 \times 10^{5} \pm 4.39 \times 10^{5} \mathrm{PFU} / \mathrm{mL}\right)$ with SARS-CoV-2 $\left(2.18 \times 10^{6} \pm 9.96 \times 10^{5}\right.$

$351 \mathrm{PFU} / \mathrm{mL}$ ), the difference was not statistically significant (Fig 2C).

352 3. WIN reduces the secretion of inflammatory cytokines in SARS-CoV-2-infected

353 hiPSC-CMs

354 The "cytokine storm" is a hallmark of severe COVID-19 cases and cannabinoids have

355 well-known anti-inflammatory properties. We asked whether WIN could reduce the

356 release of the inflammatory cytokines IL-6, IL-8, TNF- $\alpha$ by hiPSC-CMs in vitro. Cells were

357 pretreated with $1 \mu \mathrm{M}$ WIN for 24 hours, infected for 1 hour, and incubated further for 24 ,

35848 , and 72 hours. Then, the media were harvested at each time point for analysis. We

359 found that cells infected with SARS-CoV-2 released higher levels of cytokines when

360 compared with MOCK, with the exception of IL-8 at 24 and IL-6 at 72 hours post-infection

361 (Fig 3A, B, and C). Most importantly, in all conditions that significantly augmented the

362 release of these pro-inflammatory cytokines, WIN was able to prevent this increase (Fig 
$3633 \mathrm{~A}, \mathrm{~B}$, and $\mathrm{C})$. Of note, whereas the basal amount of cytokines tended to increase during

364 culture time as they accumulated without media changes, WIN did not significantly affect

365 this basal release by comparing MOCK and MOCK WIN groups.

\section{4. WIN reduces cell death in SARS-CoV-2- infected hiPSC-CMs}

367 It has been previously reported that SARS-CoV-2 infection causes apoptosis in hiPSC-

368 CMs (Perez-Bermejo et al., 2021, p.). As cannabinoids can be protective in some tissues,

369 we investigated whether WIN would protect hiPSC-CMs from cell death. Cells were

370 pretreated with $1 \mu \mathrm{M} \mathrm{WIN}$ for 24 hours, infected for 1 hour, and cultivated for additional

37124,48 , and 72 hours and LDH was measured in the media at these different time points.

372 Forty-eight and 72 hours after the infection with SARS-CoV-2 without WIN, the release of

373 LDH increased $463 \%$ and $174 \%$, respectively, in hiPSC-CMs. On the other hand, hiPSC-

374 CMs infected with SARS-CoV-2 and exposed to WIN had significantly lower increments

375 of $72 \%$ and $40 \%$, respectively (Figure $3 \mathrm{D}$ ).

376 Discussion

377 Cannabinoids have been proposed as potential treatment and prevention of COVID-19,

378 due to their antiviral, cytoprotective and anti-inflammatory properties (Marchalant, Rosi \&

379 Wenk, 2007; Rossi et al., 2020; Anil et al., 2021). In this study, we showed that the

380 synthetic CB1/CB2 agonist WIN reduced cell damage in SARS-CoV-2-infected hiPSC-

381 CMs. Additionally, even though cardiomyocytes are not known for evoking robust

382 inflammatory responses, WIN reduced the release of cytokines by these cells following

383 SARS-CoV-2 infection. To our knowledge, this is the first study showing anti-inflammatory 
384 and protective properties of a cannabinoid agonist in hiPSC-CMs infected with SARS-

385 CoV-2.

386 We hypothesized that WIN reduces the levels of ACE2 in hiPSC-CMs, consequently

387 abrogating SARS-CoV-2 infection and viral load in these cells. However, despite hiPSC-

388 CMs expressing ACE2, it only presented a tendency towards an increase which was not

389 modulated by WIN in the conditions studied here. ACE2 is downregulated in SARS-CoV-2

390 infected tissues (Yan et al., 2020; Gheblawi et al., 2020), which is harmful to the heart

391 since ACE2 has a protective role in the cardiovascular system (Huentelman et al., 2005;

392 Zhong et al., 2010). Studies have shown that agonists of cannabinoid receptors, including

393 WIN, cause vasodilation through the activation of CB1 receptors, and are capable of

394 modulating vasoactive ligands (Sainz-Cort \& Heeroma, 2020; Miklós et al., 2021). One

395 possibility for the tendency towards an increase in the levels of ACE2 in WIN-treated

396 hiPSC-CMs is that this cannabinoid agonist could exert a protective role by preventing

397 receptor downregulation. Although it has been previously shown (Wang et al., 2020) that

398 CBD-rich extracts reduced ACE2 mRNA and protein levels in some epithelia in vitro

399 following TNF- $\alpha$ insult, this modulation had not been investigated in SARS-CoV-2 infected

400 cardiomyocytes until now.

401 Despite evidence of cannabinoid receptors expression in murine embryonic stem cells

402 (Jiang et al., 2007) and human cardiomyocytes (Mukhopadhyay et al., 2010), to our

403 knowledge, this is the first description of the expression of CB1 receptor in hiPSC-CMs.

404 The modulation of cannabinoid receptors in cardiomyocytes has also not been explored

405 yet. Our results showed that WIN did not reduce the infection rate or the viral titer in

406 hiPSC-CMs in the conditions studied here. Several studies have examined the effect of 
407 cannabinoids on viral infections, especially regarding the role of CB1 and CB2 receptor 408 activation (Reiss, 2010). The CB2 receptor agonist JWH-133 reduced CXCR4-tropic HIV-

4091 infection of primary CD4+ T cells, whereas the CB1 receptor agonist arachidonoyl-29-

410 chloroethylamide had no effect. In another study with HIV-1-infected primary human

411 monocytes, agonists of CB2 receptors limited viral replication (Ramirez et al., 2013).

412 There is still no consensus on the antiviral mechanisms of cannabinoids, however, it is 413 well-known that the selective activation of the CB2 receptor plays a crucial role in the

414 course of viral infection (Rossi et al., 2020). The fact that hiPSC-CMs do not express the

415 CB2 receptor may explain WIN's ineffectiveness in reducing SARS-CoV-2 infection and

416 replication in these cells. Additionally, to date, cannabinoid treatment along with SARS-

417 CoV-2 infection had not been investigated in this cellular model. It is likely that viral 418 infection mechanisms through $\mathrm{CB} 1$ and $\mathrm{CB} 2$ receptors might vary depending on virus 419 and cell type (Reiss, 2010; Tahamtan et al., 2016).

420 Although immune cells and cardiac fibroblasts are typically the major players in cytokine 421 production under stressed cardiac conditions (Zhong et al., 2010), cardiomyocytes are 422 also a local source of proinflammatory cytokines (Yamauchi-Takihara et al., 1995; Ancey 423 et al., 2002; Kleinbongard, Schulz \& Heusch, 2011; Atefi et al., 2011; Bozzi et al., 2019). 424 In this work, hiPSC-CMs released IL-6, IL-8, and TNF- $\alpha$ at baseline levels and SARS425 CoV-2 infection increased all cytokines levels. It has been shown that infection of hiPSC426 CMs by Trypanosoma cruzi, the Chagas' disease pathogen, prompted these cells to 427 produce proinflammatory cytokines that caused autocrine cardiomyocyte dysfunction 428 (Bozzi et al., 2019). Cardiac damage in COVID-19 patients can be attributable to 429 hypoxemia due to respiratory dysfunction (Guo et al., 2020) but also to the "cytokine 
430 storm", which is the uncontrolled systemic inflammatory response likely caused by an

431 imbalance between regulatory and cytotoxic T cells (Meckiff et al., 2020). Even though

432 the "cytokine storm" is one of the hallmarks of SARS-CoV-2 infection (Coperchini et al.,

433 2020), one cannot rule out that cytokines locally released contribute to tissue damage, as

434 seen, for example, in Trypanosoma cruzi cardiac infection (Bozzi et al., 2019). Here we

435 found that WIN decreased the levels of IL-6, IL-8, and TNF- $\alpha$ released by SARS-CoV-2-

436 infected hiPSC-CMs. An in vitro study of cortical astrocytes treated with Amyloid- $\beta_{1-42}$,

437 which is a neurotoxic protein, showed that WIN reduced TNF- $\alpha$ and IL-1 $\beta$ levels, while

438 preventing cell death (Aguirre-Rueda et al., 2015). In another study, WIN decreased the

439 activity of peroxisome proliferator-activated receptor alpha and TNF- $\alpha$ levels in the heart

440 tissue of mice with cardiac dysfunction (Rahmatollahi et al., 2016), reinforcing its anti-

441 inflammatory and protective properties in cardiac tissue.

442 THC and WIN are structurally different and accordingly have different efficacies towards

443 activation of cannabinoid signaling pathways (Soethoudt et al., 2017). However, they are

444 both mutual CB1 and CB2 receptor agonists (Compton et al., 1992) and can produce

445 similar pharmacological effects, depending on the assay (Fan et al., 1994). THC

446 presented a protective role against hypoxia in neonatal murine cardiomyocytes by

447 reducing the levels of LDH (Shmist et al., 2006). Since neonatal murine cardiomyocytes

448 expressed CB2, but not CB1, the authors suggest that cardioprotection provided by THC

449 occurs via the CB2 receptor. Herein, we were able to show that hiPSC-CMs expressed

450 only CB1 but not CB2. In human cardiomyocytes, WIN decreased the release of LDH

451 release and this effect could be mediated by CB1, to which WIN has high affinity. Other

452 receptor candidates, such as transient receptor potential vanilloid (TRPV) channels 
453 (Freichel et al., 2017) can not be discarded. Nonetheless, the modulation of TRPV 454 channels by WIN occurs at $10 \mu \mathrm{M}$ or higher (Jeske et al., 2006; Koch et al., 2011), which 455 are, at least, 10 times above the concentration used in our study.

\section{Conclusion}

457 This study showed that pretreatment with a cannabinoid receptor agonist reduced 458 cytotoxicity and proinflammatory cytokines released by human cardiomyocytes infected with SARS-CoV-2. These results suggest that the therapeutic potential of cannabinoids

460 in protecting the heart against SARS-CoV-2 infection should be further explored, in 461 particular regarding selective action on the CB1 receptor.

\section{References}

Aguirre-Rueda D, Guerra-Ojeda S, Aldasoro M, Iradi A, Obrador E, Mauricio MD, Vila JM, Marchio P, Valles SL. 2015. WIN 55,212-2, Agonist of Cannabinoid Receptors, Prevents Amyloid $\beta 1$ 42 Effects on Astrocytes in Primary Culture. PLOS ONE 10:e0122843. DOI: 10.1371/journal.pone.0122843.

Albakri A. 2019. Drugs-related cardiomyopathy: A systematic review and pooled analysis of pathophysiology, diagnosis and clinical management. Internal Medicine and Care 3. DOI: 10.15761/IMC.1000129.

Ancey C, Corbi P, Froger J, Delwail A, Wijdenes J, Gascan H, Potreau D, Lecron J-C. 2002. Secretion of IL-6, IL-11 and LIF by human cardiomyocytes in primary culture. Cytokine 18:199-205. DOI: 10.1006/cyto.2002.1033.

Anil SM, Shalev N, Vinayaka AC, Nadarajan S, Namdar D, Belausov E, Shoval I, Mani KA, Mechrez G, Koltai H. 2021. Cannabis compounds exhibit anti-inflammatory activity in vitro in 
475

476

477

478

479

480

481

482

483

484

485

486

487

488

489

490

491

492

493

494

495

496

497

498

499

500

COVID-19-related inflammation in lung epithelial cells and pro-inflammatory activity in macrophages. Scientific Reports 11:1462. DOI: 10.1038/s41598-021-81049-2.

Aromolaran AS, Srivastava U, Alí A, Chahine M, Lazaro D, El-Sherif N, Capecchi PL, Laghi-Pasini F, Lazzerini PE, Boutjdir M. 2018. Interleukin-6 inhibition of hERG underlies risk for acquired long QT in cardiac and systemic inflammation. PloS One 13:e0208321. DOI: 10.1371/journal.pone.0208321.

Atefi G, Zetoune FS, Herron TJ, Jalife J, Bosmann M, Al-Aref R, Sarma JV, Ward PA. 2011. Complement dependency of cardiomyocyte release of mediators during sepsis. The FASEB Journal 25:2500-2508. DOI: 10.1096/fj.11-183236.

Bozzi A, Sayed N, Matsa E, Sass G, Neofytou E, Clemons KV, Correa-Oliveira R, Stevens DA, Wu JC. 2019. Using Human Induced Pluripotent Stem Cell-Derived Cardiomyocytes as a Model to Study Trypanosoma cruzi Infection. Stem Cell Reports 12:1232-1241. DOI: 10.1016/j.stemcr.2019.04.017.

Carod-Artal FJ. 2020. Neurological complications of coronavirus and COVID-19. Revista De Neurologia 70:311-322. DOI: 10.33588/rn.7009.2020179.

Chen L, Li X, Chen M, Feng Y, Xiong C. 2020a. The ACE2 expression in human heart indicates new potential mechanism of heart injury among patients infected with SARS-CoV-2. Cardiovascular Research 116:1097-1100. DOI: 10.1093/cvr/cvaa078.

Chen N, Zhou M, Dong X, Qu J, Gong F, Han Y, Qiu Y, Wang J, Liu Y, Wei Y, Xia J, Yu T, Zhang X, Zhang L. 2020b. Epidemiological and clinical characteristics of 99 cases of 2019 novel coronavirus pneumonia in Wuhan, China: a descriptive study. The Lancet 395:507-513. DOI: 10.1016/S0140-6736(20)30211-7.

Compton DR, Gold LH, Ward SJ, Balster RL, Martin BR. 1992. Aminoalkylindole analogs: cannabimimetic activity of a class of compounds structurally distinct from delta 9tetrahydrocannabinol. The Journal of Pharmacology and Experimental Therapeutics 263:1118-1126. 
501 Dariolli R, Campana C, Gutierrez A, Sobie EA. 2021. In vitro and in silico models to study SARS-

502 CoV-2 infection: integrating experimental and computational tools to mimic \&quot;COVID-19

503 cardiomyocyte\&quot; Frontiers in Physiology 12. DOI: 10.3389/fphys.2021.624185.

504 Devane WA, Dysarz FA, Johnson MR, Melvin LS, Howlett AC. 1988. Determination and 505 characterization of a cannabinoid receptor in rat brain. Molecular Pharmacology 34:605-613.

506 Diaz-Guimaraens B, Dominguez-Santas M, Suarez-Valle A, Pindado-Ortega C, Selda-Enriquez

507 G, Bea-Ardebol S, Fernandez-Nieto D. 2020. Petechial Skin Rash Associated With Severe

508 Acute Respiratory Syndrome Coronavirus 2 Infection. JAMA Dermatology 156:820. DOI:

$509 \quad$ 10.1001/jamadermatol.2020.1741.

510 Dolhnikoff M. 2020. SARS-CoV-2 in cardiac tissue of a child with COVID-19-related multisystem 511 inflammatory syndrome. 4:5.

512 Fan F, Compton DR, Ward S, Melvin L, Martin BR. 1994. Development of cross-tolerance

513 between delta 9-tetrahydrocannabinol, CP 55,940 and WIN 55,212. The Journal of

$514 \quad$ Pharmacology and Experimental Therapeutics 271:1383-1390.

515 Felder CC, Joyce KE, Briley EM, Mansouri J, Mackie K, Blond O, Lai Y, Ma AL, Mitchell RL. 1995.

516 Comparison of the pharmacology and signal transduction of the human cannabinoid CB1 and 517 CB2 receptors. Molecular Pharmacology 48:443-450.

518 Feng Y-J, Li Y-Y, Lin X-H, Li K, Cao M-H. 2016. Anti-inflammatory effect of cannabinoid agonist 519 WIN55, 212 on mouse experimental colitis is related to inhibition of p38MAPK. World Journal 520 of Gastroenterology 22:9515-9524. DOI: 10.3748/wjg.v22.i43.9515.

521 Freichel M, Berlin M, Schürger A, Mathar I, Bacmeister L, Medert R, Frede W, Marx A, Segin S, 522 Londoño JEC. 2017. TRP Channels in the Heart. In: Emir TLR ed. Neurobiology of TRP 523 Channels. Frontiers in Neuroscience. Boca Raton (FL): CRC Press/Taylor \& Francis,.

524 Gheblawi M, Wang K, Viveiros A, Nguyen Q, Zhong J-C, Turner AJ, Raizada MK, Grant MB, Oudit 525 GY. 2020. Angiotensin-Converting Enzyme 2: SARS-CoV-2 Receptor and Regulator of the 
Renin-Angiotensin System: Celebrating the 20th Anniversary of the Discovery of ACE2.

Gomes IC, Karmirian K, Oliveira J, Pedrosa C, Rosman FC, Chimelli L, Rehen S. 2020. SARSCoV-2 Infection in the Central Nervous System of a 1-Year-Old Infant Submitted to Complete Autopsy. DOI: 10.20944/preprints202009.0297.v1.

531

532

533

534

535

536

537

538

539

Guo J, Huang Z, Lin L, Lv J. 2020. Coronavirus Disease 2019 (COVID-19) and Cardiovascular Disease: A Viewpoint on the Potential Influence of Angiotensin-Converting Enzyme Inhibitors/Angiotensin Receptor Blockers on Onset and Severity of Severe Acute Respiratory Syndrome Coronavirus 2 Infection. Journal of the American Heart Association 9:e016219. DOI: 10.1161/JAHA.120.016219.

Huentelman MJ, Grobe JL, Vazquez J, Stewart JM, Mecca AP, Katovich MJ, Ferrario CM, Raizada MK. 2005. Protection from angiotensin II-induced cardiac hypertrophy and fibrosis by systemic lentiviral delivery of ACE2 in rats. Experimental Physiology 90:783-790. DOI: 10.1113/expphysiol.2005.031096.

Jeske NA, Patwardhan AM, Gamper N, Price TJ, Akopian AN, Hargreaves KM. 2006. Cannabinoid WIN 55,212-2 regulates TRPV1 phosphorylation in sensory neurons. The Journal of Biological Chemistry 281:32879-32890. DOI: 10.1074/jbc.M603220200.

Jiang S, Fu Y, Williams J, Wood J, Pandarinathan L, Avraham S, Makriyannis A, Avraham S, Avraham HK. 2007. Expression and Function of Cannabinoid Receptors CB1 and CB2 and Their Cognate Cannabinoid Ligands in Murine Embryonic Stem Cells. PLOS ONE 2:e641. DOI: 10.1371/journal.pone.0000641.

Keck M, Flamant M, Mougenot N, Favier S, Atassi F, Barbier C, Nadaud S, Lompré A-M, Hulot JS, Pavoine C. 2019. Cardiac inflammatory CD11b/c cells exert a protective role in hypertrophied cardiomyocyte by promoting TNFR 2 - and Orai3- dependent signaling. Scientific Reports 9:6047. DOI: 10.1038/s41598-019-42452-y. 
551 Kleinbongard P, Schulz R, Heusch G. 2011. TNFa in myocardial ischemia/reperfusion,

552 remodeling and heart failure. Heart Failure Reviews 16:49-69. DOI: 10.1007/s10741-010$5539180-8$.

554 Koch M, Kreutz S, Böttger C, Grabiec U, Ghadban C, Korf H-W, Dehghani F. 2011. The 555 cannabinoid WIN 55,212-2-mediated protection of dentate gyrus granule cells is driven by 556 CB1 receptors and modulated by TRPA1 and Cav 2.2 channels. Hippocampus 21:554-564. 557 DOI: 10.1002/hipo.20772.

558 Kwon Y, Nukala SB, Srivastava S, Miyamoto H, Ismail NI, Jousma J, Rehman J, Ong S-B, Lee 559 WH, Ong S-G. 2020. Detection of viral RNA fragments in human iPSC cardiomyocytes 560 following treatment with extracellular vesicles from SARS-CoV-2 coding sequence 561 overexpressing lung epithelial cells. Stem Cell Research \& Therapy 11:514. DOI: 10.1186/s13287-020-02033-7.

563 Lei X, Dong X, Ma R, Wang W, Xiao X, Tian Z, Wang C, Wang Y, Li L, Ren L, Guo F, Zhao Z, 564 Zhou Z, Xiang Z, Wang J. 2020. Activation and evasion of type I interferon responses by 565 SARS-CoV-2. Nature Communications 11. DOI: 10.1038/s41467-020-17665-9.

Lindner D, Fitzek A, Bräuninger H, Aleshcheva G, Edler C, Meissner K, Scherschel K, Kirchhof 567 P, Escher F, Schultheiss H-P, Blankenberg S, Püschel K, Westermann D. 2020. Association of Cardiac Infection With SARS-CoV-2 in Confirmed COVID-19 Autopsy Cases. JAMA Cardiology 5:1281. DOI: 10.1001/jamacardio.2020.3551.

Mahé A, Birckel E, Krieger S, Merklen C, Bottlaender L. 2020. A distinctive skin rash associated with coronavirus disease 2019? Journal of the European Academy of Dermatology and Venereology: JEADV 34:e246-e247. DOI: 10.1111/jdv.16471.

573 Maisch B. 2020. SARS-CoV-2 as potential cause of cardiac inflammation and heart failure. Is it 574 the virus, hyperinflammation, or MODS? Herz:1-2. DOI: 10.1007/s00059-020-04925-z. 
575 Marchalant Y, Rosi S, Wenk GL. 2007. Anti-inflammatory property of the cannabinoid agonist 576 WIN-55212-2 in a rodent model of chronic brain inflammation. Neuroscience 144:1516-1522.

577 DOI: 10.1016/j.neuroscience.2006.11.016.

578 Meckiff BJ, Ramírez-Suástegui C, Fajardo V, Chee SJ, Kusnadi A, Simon H, Eschweiler S, Grifoni 579 A, Pelosi E, Weiskopf D, Sette A, Ay F, Seumois G, Ottensmeier CH, Vijayanand P. 2020. 580 Imbalance of Regulatory and Cytotoxic SARS-CoV-2-Reactive CD4+ T Cells in COVID-19. 581 Cell 183:1340-1353.e16. DOI: 10.1016/j.cell.2020.10.001.

Medina-Vera D, Rosell-Valle C, López-Gambero AJ, Navarro JA, Zambrana-Infantes EN, Rivera P, Santín LJ, Suarez J, Rodríguez de Fonseca F. 2020. Imbalance of Endocannabinoid/Lysophosphatidylinositol Receptors Marks the Severity of Alzheimer's Disease in a Preclinical Model: A Therapeutic Opportunity. Biology 9:377. DOI: 10.3390/biology9110377.

Mendizábal VE, Adler-Graschinsky E. 2007. Cannabinoids as therapeutic agents in cardiovascular disease: a tale of passions and illusions. British Journal of Pharmacology 151:427-440. DOI: 10.1038/sj.bjp.0707261.

Miklós Z, Wafa D, Nádasy GL, Tóth ZE, Besztercei B, Dörnyei G, Laska Z, Benyó Z, Ivanics T, Hunyady L, Szekeres M. 2021. Angiotensin II-Induced Cardiac Effects Are Modulated by 10.3390/cells10040724.

Mukhopadhyay P, Rajesh M, Bátkai S, Patel V, Kashiwaya Y, Liaudet L, Evgenov OV, Mackie K, Haskó G, Pacher P. 2010. CB1 cannabinoid receptors promote oxidative stress and cell death in murine models of doxorubicin-induced cardiomyopathy and in human cardiomyocytes. Cardiovascular Research 85:773-784. DOI: 10.1093/cvr/cvp369.

Munro S, Thomas KL, Abu-Shaar M. 1993. Molecular characterization of a peripheral receptor for cannabinoids. Nature 365:61-65. DOI: 10.1038/365061a0. 
600 Nguyen LC, Yang D, Nicolaescu V, Best TJ, Ohtsuki T, Chen S-N, Friesen JB, Drayman N, 601 Mohamed A, Dann C, Silva D, Gula H, Jones KA, Millis JM, Dickinson BC, Tay S, Oakes SA, 602 Pauli GF, Meltzer DO, Randall G, Rosner MR. 2021. Cannabidiol Inhibits SARS-CoV-2 603 Replication and Promotes the Host Innate Immune Response. bioRxiv:2021.03.10.432967. $604 \quad$ DOI: $10.1101 / 2021.03 .10 .432967$.

605 Pacher P, Steffens S, Haskó G, Schindler TH, Kunos G. 2018. Cardiovascular effects of 606 marijuana and synthetic cannabinoids: the good, the bad, and the ugly. Nature Reviews 607 Cardiology 15:151-166. DOI: 10.1038/nrcardio.2017.130.

Perez-Bermejo JA, Kang S, Rockwood SJ, Simoneau CR, Joy DA, Silva AC, Ramadoss GN, Flanigan WR, Fozouni P, Li H, Chen P-Y, Nakamura K, Whitman JD, Hanson PJ, McManus

613 Puelles VG, Lütgehetmann M, Lindenmeyer MT, Sperhake JP, Wong MN, Allweiss L, Chilla S, 614 Heinemann A, Wanner N, Liu S, Braun F, Lu S, Pfefferle S, Schröder AS, Edler C, Gross O, 615 Glatzel M, Wichmann D, Wiech T, Kluge S, Pueschel K, Aepfelbacher M, Huber TB. 2020. 616 Multiorgan and Renal Tropism of SARS-CoV-2. New England Journal of Medicine 383:590592. DOI: 10.1056/NEJMc2011400.

618 Rahmatollahi M, Baram SM, Rahimian R, Saeedi Saravi SS, Dehpour AR. 2016. Peroxisome 619 Proliferator-Activated Receptor- $\alpha$ Inhibition Protects Against Doxorubicin-Induced 620 Cardiotoxicity in Mice. Cardiovascular Toxicology 16:244-250. DOI: 10.1007/s12012-015$6219332-0$.

622 Ramirez SH, Reichenbach NL, Fan S, Rom S, Merkel SF, Wang X, Ho W-Z, Persidsky Y. 2013. 623 Attenuation of HIV-1 replication in macrophages by cannabinoid receptor 2 agonists. Journal 624 of Leukocyte Biology 93:801-810. DOI: 10.1189/jlb.1012523. 
625 Reiss CS. 2010. Cannabinoids and Viral Infections. Pharmaceuticals 3:1873-1886. DOI: $626 \quad 10.3390 / p h 3061873$.

627 Rossi F, Tortora C, Argenziano M, Di Paola A, Punzo F. 2020. Cannabinoid Receptor Type 2: A 628 Possible Target in SARS-CoV-2 (CoV-19) Infection? International Journal of Molecular 629 Sciences 21. DOI: 10.3390/ijms21113809.

630 Sachdev S, Vemuri K, Banister SD, Longworth M, Kassiou M, Santiago M, Makriyannis A, Connor 631 M. 2019. In vitro determination of the efficacy of illicit synthetic cannabinoids at CB1 receptors. 632 British Journal of Pharmacology 176:4653-4665. DOI: 10.1111/bph.14829.

633 Sainz-Cort A, Heeroma JH. 2020. The interaction between the endocannabinoid system and the 634 renin angiotensin system and its potential implication for COVID-19 infection. Journal of Cannabis Research 2:23. DOI: 10.1186/s42238-020-00030-4.

636 Salerno JA, Torquato T, Temerozo JR, Goto-Silva L, Mendes M, Sacramento CQ, Fintelman637 Rodrigues N, Vitoria G, Souza L, Ornelas I, Veríssimo C, Karmirian K, Pedrosa C, Dias S da 638 SG, Soares VC, Aragão LGH, Puig-Pijuan T, Salazar VW, Dariolli R, Biagi D, Furtado DR, 639 Borges HL, Bozza P, Guimarães MZ, Souza TML, Rehen SK. 2021. Inhibition of SARS-CoV-2 640 infection in human cardiomyocytes by targeting the Sigma-1 receptor disrupts cytoskeleton 641 architecture and contractility. bioRxiv:2021.02.20.432092. DOI: 10.1101/2021.02.20.432092. 642 Sharma A, Garcia G, Wang Y, Plummer JT, Morizono K, Arumugaswami V, Svendsen CN. 2020. 643 644 Human iPSC-Derived Cardiomyocytes Are Susceptible to SARS-CoV-2 Infection. Cell Reports Medicine 1:100052. DOI: 10.1016/j.xcrm.2020.100052.

Shmist YA, Goncharov I, Eichler M, Shneyvays V, Isaac A, Vogel Z, Shainberg A. 2006. Delta-9tetrahydrocannabinol protects cardiac cells from hypoxia via CB2 receptor activation and nitric oxide production. Molecular and Cellular Biochemistry 283:75-83. DOI: 10.1007/s11010-0062346-y.

Smeets PJH, Teunissen BEJ, Planavila A, de Vogel-van den Bosch H, Willemsen PHM, van der Vusse GJ, van Bilsen M. 2008. Inflammatory Pathways Are Activated during Cardiomyocyte 
Hypertrophy and Attenuated by Peroxisome Proliferator-activated Receptors PPARa and PPARס. The Journal of Biological Chemistry 283:29109-29118. DOI: 10.1074/jbc.M802143200.

654 Smith SR, Terminelli C, Denhardt G. 2000. Effects of cannabinoid receptor agonist and antagonist 655 ligands on production of inflammatory cytokines and anti-inflammatory interleukin-10 in 656 endotoxemic mice. The Journal of Pharmacology and Experimental Therapeutics 293:136$657 \quad 150$.

658 Soethoudt M, Grether U, Fingerle J, Grim TW, Fezza F, de Petrocellis L, Ullmer C, Rothenhäusler 659 B, Perret C, van Gils N, Finlay D, MacDonald C, Chicca A, Gens MD, Stuart J, de Vries H, 660 Mastrangelo N, Xia L, Alachouzos G, Baggelaar MP, Martella A, Mock ED, Deng H, Heitman LH, Connor M, Di Marzo V, Gertsch J, Lichtman AH, Maccarrone M, Pacher P, Glass M, van der Stelt M. 2017. Cannabinoid CB 2 receptor ligand profiling reveals biased signalling and off-target activity. Nature Communications 8:13958. DOI: 10.1038/ncomms13958.

Tahamtan A, Tavakoli-Yaraki M, Rygiel TP, Mokhtari-Azad T, Salimi V. 2016. Effects of cannabinoids and their receptors on viral infections. Journal of Medical Virology 88:1-12. DOI: 10.1002/jmv.24292.

Thum T. 2020. SARS-CoV-2 receptor ACE2 expression in the human heart: cause of a postpandemic wave of heart failure? European Heart Journal 41:1807-1809. DOI: 10.1093/eurheartj/ehaa410.

Unudurthi SD, Luthra P, Bose RJC, McCarthy JR, Kontaridis MI. 2020. Cardiac inflammation in COVID-19: Lessons from heart failure. Life Sciences 260:118482. DOI: 10.1016/j.Ifs.2020.118482.

Varga Z, Flammer AJ, Steiger P, Haberecker M, Andermatt R, Zinkernagel AS, Mehra MR, 675 Schuepbach RA, Ruschitzka F, Moch H. 2020. Endothelial cell infection and endotheliitis in COVID-19. The Lancet 395:1417-1418. DOI: 10.1016/S0140-6736(20)30937-5. 
676 Wang B, Kovalchuk A, Li D, Rodriguez-Juarez R, Ilnytskyy Y, Kovalchuk I, Kovalchuk O. 2020. In 677 search of preventive strategies: novel high-CBD Cannabis sativa extracts modulate ACE2 678 expression in COVID-19 gateway tissues. Aging 12:22425-22444. DOI: $679 \quad$ 10.18632/aging.202225.

680 Wang J-H, Zhao L, Pan X, Chen N-N, Chen J, Gong Q-L, Su F, Yan J, Zhang Y, Zhang S-H. 681 2016. Hypoxia-stimulated cardiac fibroblast production of IL-6 promotes myocardial fibrosis 682 via the TGF- $\beta 1$ signaling pathway. Laboratory Investigation 96:839-852. DOI: $683 \quad 10.1038 /$ labinvest.2016.65.

684 Wenzel DG. 1967. Drug-induced cardiomyopathies. Journal of Pharmaceutical Sciences $685 \quad 56: 1209-1224$. DOI: 10.1002/jps.2600561002.

686 Wong C-K, Luk HK-H, Lai W-H, Lau Y-M, Zhang RR, Wong AC-P, Lo GC-S, Chan K-H, Hung IF687 N, Tse H-F, Woo PC-Y, Lau SK-P, Siu C-W. 2020. Human-Induced Pluripotent Stem Cell688

691 Yamauchi-Takihara K, Ihara Y, Ogata A, Yoshizaki K, Azuma J, Kishimoto T. 1995. Hypoxic stress 692 induces cardiac myocyte-derived interleukin-6. Circulation 91:1520-1524. DOI: 10.1161/01.cir.91.5.1520.

694 Yan R, Zhang Y, Li Y, Xia L, Guo Y, Zhou Q. 2020. Structural basis for the recognition of SARS695 CoV-2 by full-length human ACE2. Science 367:1444-1448. DOI: 10.1126/science.abb2762. Zheng Y-Y, Ma Y-T, Zhang J-Y, Xie X. 2020. COVID-19 and the cardiovascular system. Nature Reviews Cardiology 17:259-260. DOI: 10.1038/s41569-020-0360-5.

698 Zhong J, Basu R, Guo D, Chow FL, Byrns S, Schuster M, Loibner H, Wang X, Penninger JM, 699 Kassiri Z, Oudit GY. 2010. Angiotensin-converting enzyme 2 suppresses pathological 700 hypertrophy, myocardial fibrosis, and cardiac dysfunction. Circulation 122:717-728, 18 p 701 following 728. DOI: 10.1161/CIRCULATIONAHA.110.955369. 
702 Zhou B, She J, Wang Y, Ma X. 2020. The clinical characteristics of myocardial injury in severe 703 and very severe patients with 2019 novel coronavirus disease. The Journal of Infection 704 81:147-178. DOI: 10.1016/j.jinf.2020.03.021.

705 
Figure 1

WIN does not modulate ACE2 in hiPSC-CMs

(A) Relative mRNA expression levels of ACE2 in WIN-treated hiPSC-CMs expressed as fold change relative to untreated condition. (B) Quantification of western blots by densitometry normalized by actin expression. ACE2 mRNA and protein levels were comparable between WIN-treated and untreated hiPSC-CMs. Error bars represent standard errors of the means (SEMs) from three (A) and four (B) independent experiments (3 or 4 cellular differentiation) from one cell line.

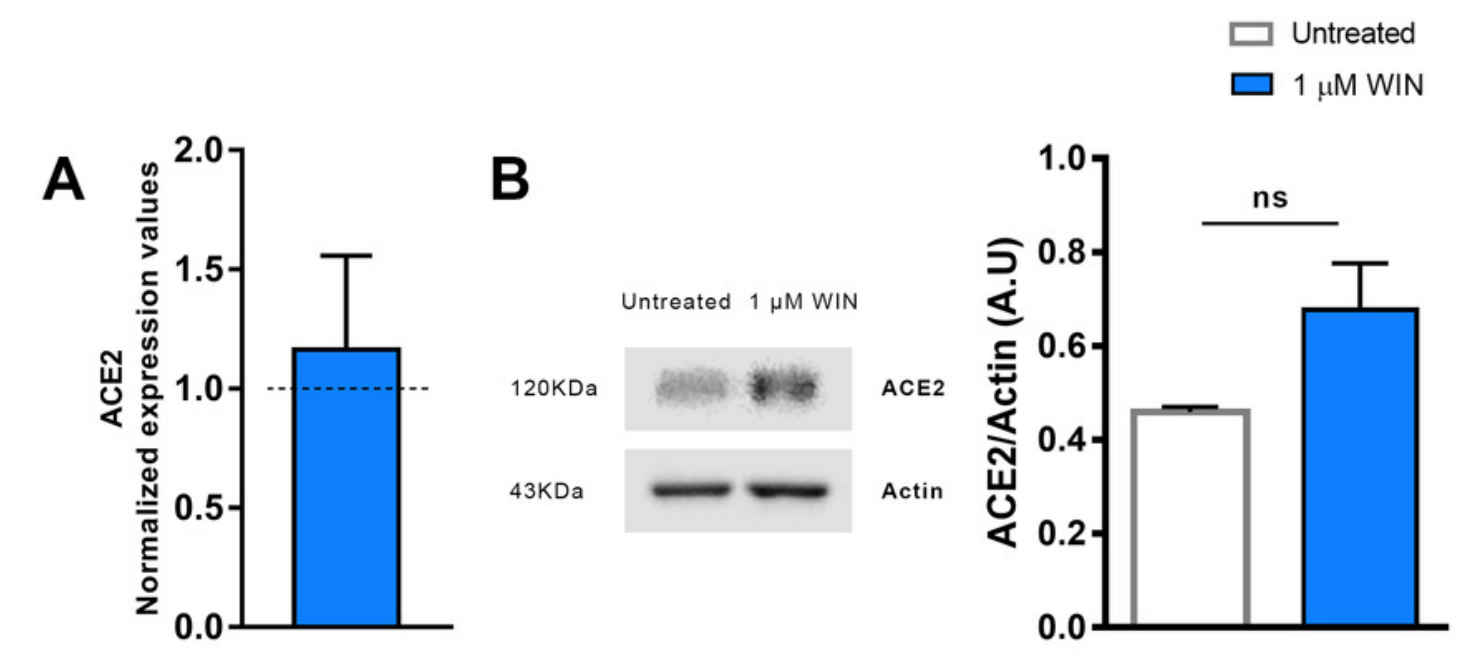




\section{Figure 2}

WIN does not reduce SARS-CoV-2 infection and replication in hiPSC-CMs

(A) Representative micrographs of MOCK and SARS-CoV-2-infected hiPSC-CM pre-treated or not with $1 \mu \mathrm{M}$ WIN for 24 hours. hiPSC-CM were immunostained with SARS-CoV-2 convalescent serum (CS) (red) and counterstained with DAPI (blue) at $48 \mathrm{~h}$ post-infection.

Scale bar: $50 \mu \mathrm{m}$. (B) Percentage of CS positive cells. CS immunoreactivity was comparable between treated and untreated hiPSC-CM. (C) Viral titer quantification by plaque forming units assay using the supernatants of the SARS-CoV-2 infected hiPSC-CMs. Viral titer was comparable between treated and untreated hiPSC-CM. Error bars represent standard errors of the means (SEM) from three independent experiments ( 3 cellular differentiations and 3 independent infections) from one iPSC line. 
A
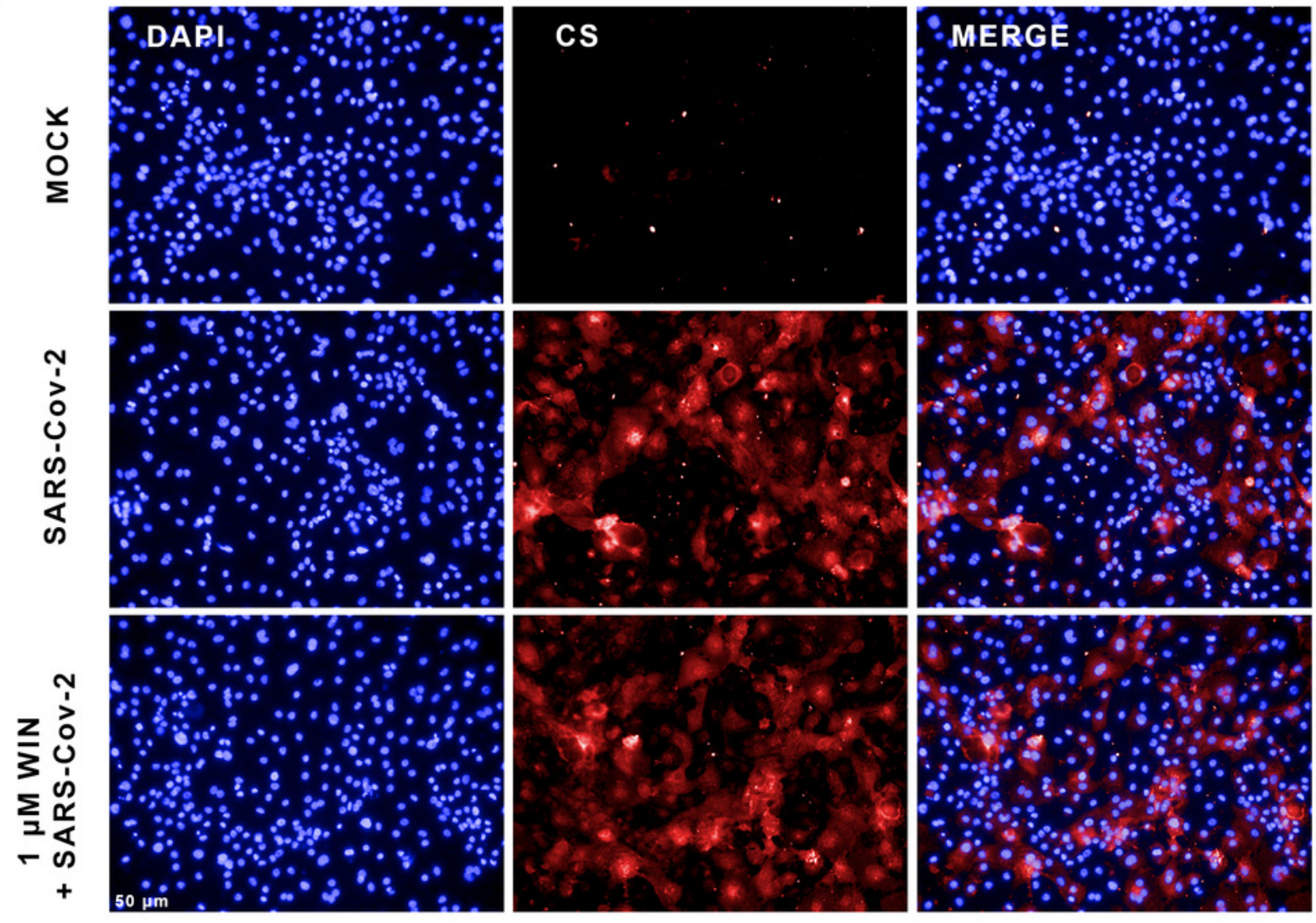

B
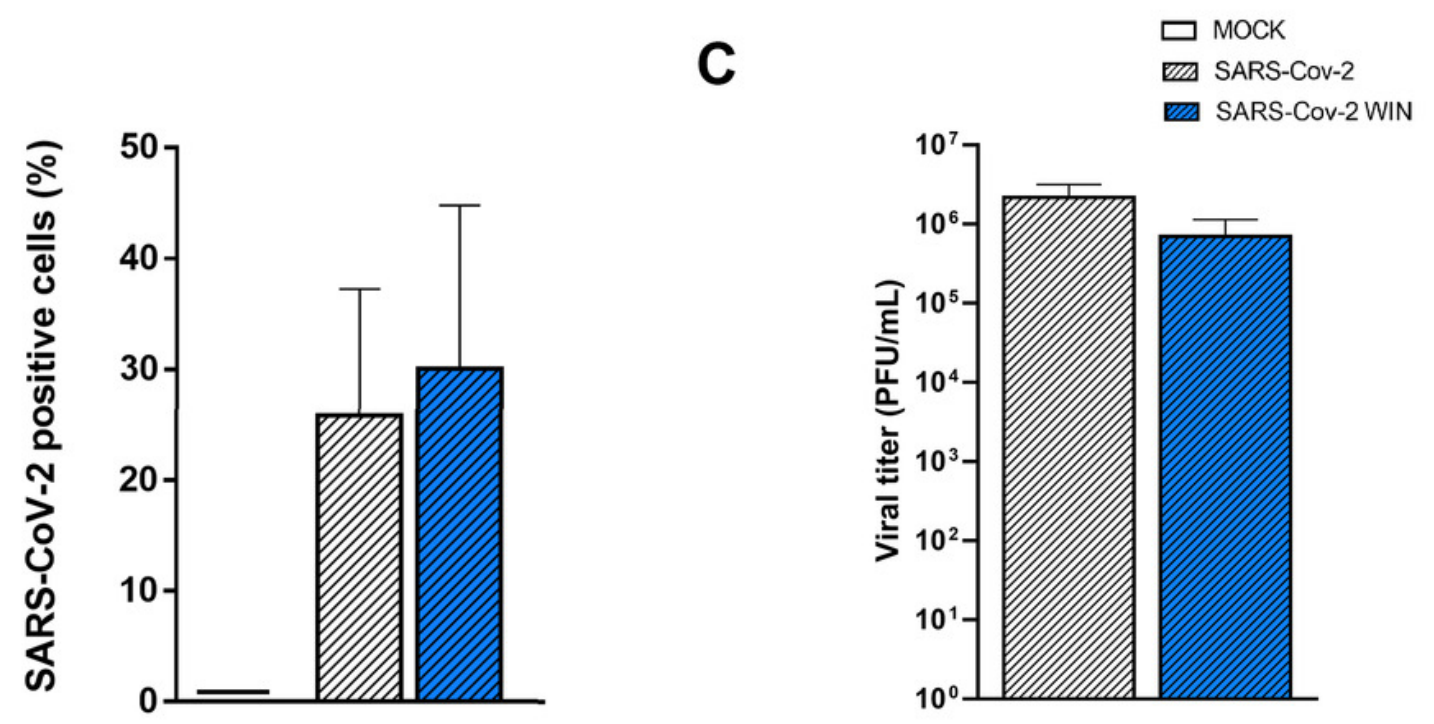


\section{Figure 3}

WIN reduces inflammatory markers and viral toxicity in hiPSC-CMs

Levels of IL-6 (A), IL-8 (B), TNF- $\alpha$ (C), and (D) release of lactate dehydrogenase (LDH) from MOCK and SARS-CoV-2-infected hiPSC-CM, treated or not with $1 \mu \mathrm{M}$ WIN for 24 hours, were analyzed at 24-, 48- and 72-hours post-infection (h.p.i.). Cytokine levels were higher in SARS-

CoV-2 compared with control (MOCK), and lower in SARS-CoV-2 WIN when compared with SARS-CoV-2. LDH release-absorbance levels relative to MOCK was higher in SARS-CoV-2 compared with SARS-CoV-2 WIN. Data represent means and standard errors of the means (SEM) from three independent experiments from one cell line. ${ }^{*} p<0.05$, ** $p<0.01, * * p<$ $0.001, * * * * p<0.0001$. 


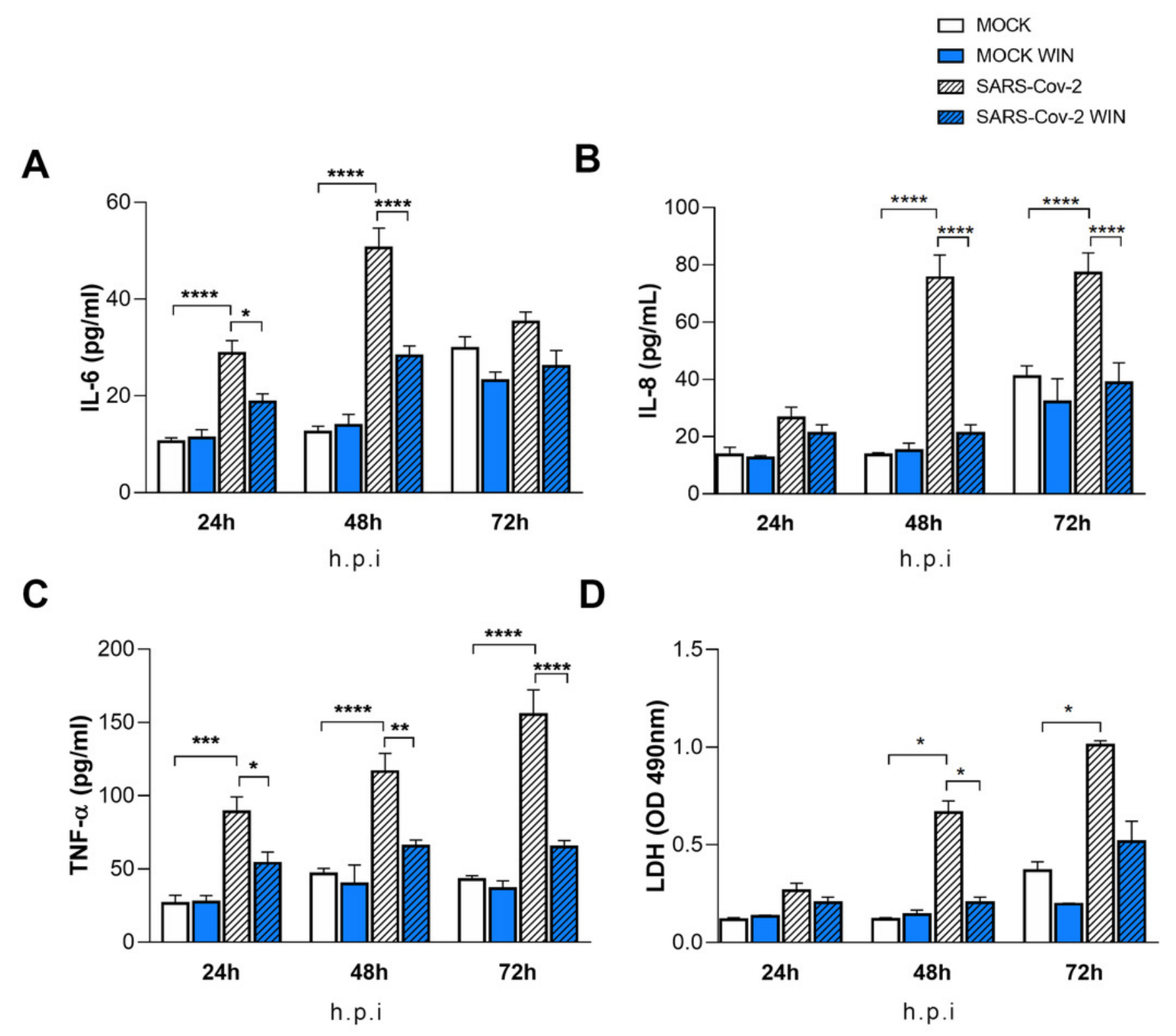

